\title{
An interesting case of pacemaker endocarditis
}

\author{
K. K. Sahu · A. K. Mishra - A. A. Sherif - A. Doshi - B. Koirala
}

Published online: 25 July 2019

(c) The Author(s) 2019

\section{Answer}

We changed antibiotics to vancomycin and cefazolin suspecting it to be Staphylococcus aureus bacteraemia. On follow-up, the sputum culture grew Staphylococcus aureus and the blood culture grew Aerococcus urinae. Source of bacteraemia was not clear as his urine culture was positive for Pseudomonas aeruginosa, which was likely due to colonisation. Suspicion of infective endocarditis (IE) remained high and was evaluated with transoesophageal echocardiography (TEE) which showed a right atrial pacer lead vegetation $(1 \times 1 \mathrm{~cm})$ and an another $1.5 \times 1.4 \mathrm{~cm}$ echo-dense structure on the right coronary cusps of aortic valve (Fig. 1b, d). Patient was continued on antibiotics, unfortunately he succumbed to illness before he could be taken up for aortic valve replacement and pacemaker removal. As per modified Duke's criteria, our patient qualified for IE (1 major criterion: positive findings in TEE, $3 \mathrm{mi}-$ nor criteria: predisposing heart conditions, temperature $>38.0^{\circ} \mathrm{C}\left(100.4^{\circ} \mathrm{F}\right)$, microbiological evidence of positive blood culture, but does not meet a major criterion).

Aerococcus is a Gram-positive, alpha haemolytic, catalase-negative cocci which is a rare cause of urinary tract infection in elderly. First reported in 1989, it

\section{K. K. Sahu (西) · A. K. Mishra · A. A. Sherif}

Department of Internal Medicine, Saint Vincent Hospital, Worcester, Massachusetts, United States drkksahu85@gmail.com

\section{A. Doshi}

Department of Cardiovascular diseases, Saint Vincent

Hospital, Worcester, Massachusetts, United States

\section{B. Koirala}

Department of Internal Medicine, Reliant Medical Group, Saint Vincent Hospital, Worcester, Massachusetts, United States is now known to cause clinically significant infections, such as soft tissue infections, urinary tract infections, septicaemia, endocarditis. Recently, Yabes et al. did a review of 43 cases of Aerococcus urinae-associated infective endocarditis [1]. They found that only 29 of these cases had documented urinary tract-related pathologies or procedures (including cystoscopy, urethral stricture, BPH, indwelling catheter). Similarly, in the study by Christensen et al., the urinary tract system was considered as the focus of infection in 16 out of 17 cases, however, Aerococcus was isolated from the urine of only nine patients [2]. Recently, many newer laboratory and imaging studies have improved the detection of rare cardiac myocardial and valvular pathologies [3-6, 7].

Aerococcus in Gram stain classically has tetrad morphology, but can also appear in clusters and irregular pairs and can be, at times, confused with Staphylococcus. Catalase negativity can be helpful in differentiating these two morphologically similar species. Also, to note that, in the blood agar, Aerococcus usually displays alpha haemolysis (resembling streptococci). $16 \mathrm{~S}$ rRNA gene sequencing and matrix-assisted laser desorption ionisation time of flight mass spectrometry (MALDI-TOF-MS) are increasingly being used for Aerococcus identification [8]. Unfortunately, due to the rarity, we lack controlled scientific trials and formalised guidelines. In most cases, therapy is often empirical and based on expert opinion. 
Fig. 1 a Short axis view and $\mathbf{b}$ long axis view at the level of mid oesophagus showing $1.5 \times 1.4 \mathrm{~cm}$ echodense structure on the right coronary cusps of the aortic valve. Upper oesophageal view c showing right atrial pacer lead with thin filamentous $1-\mathrm{cm}$ long freely mobile echo-dense structure and $\mathbf{d}$ Doppler showing severe aortic regurgitation
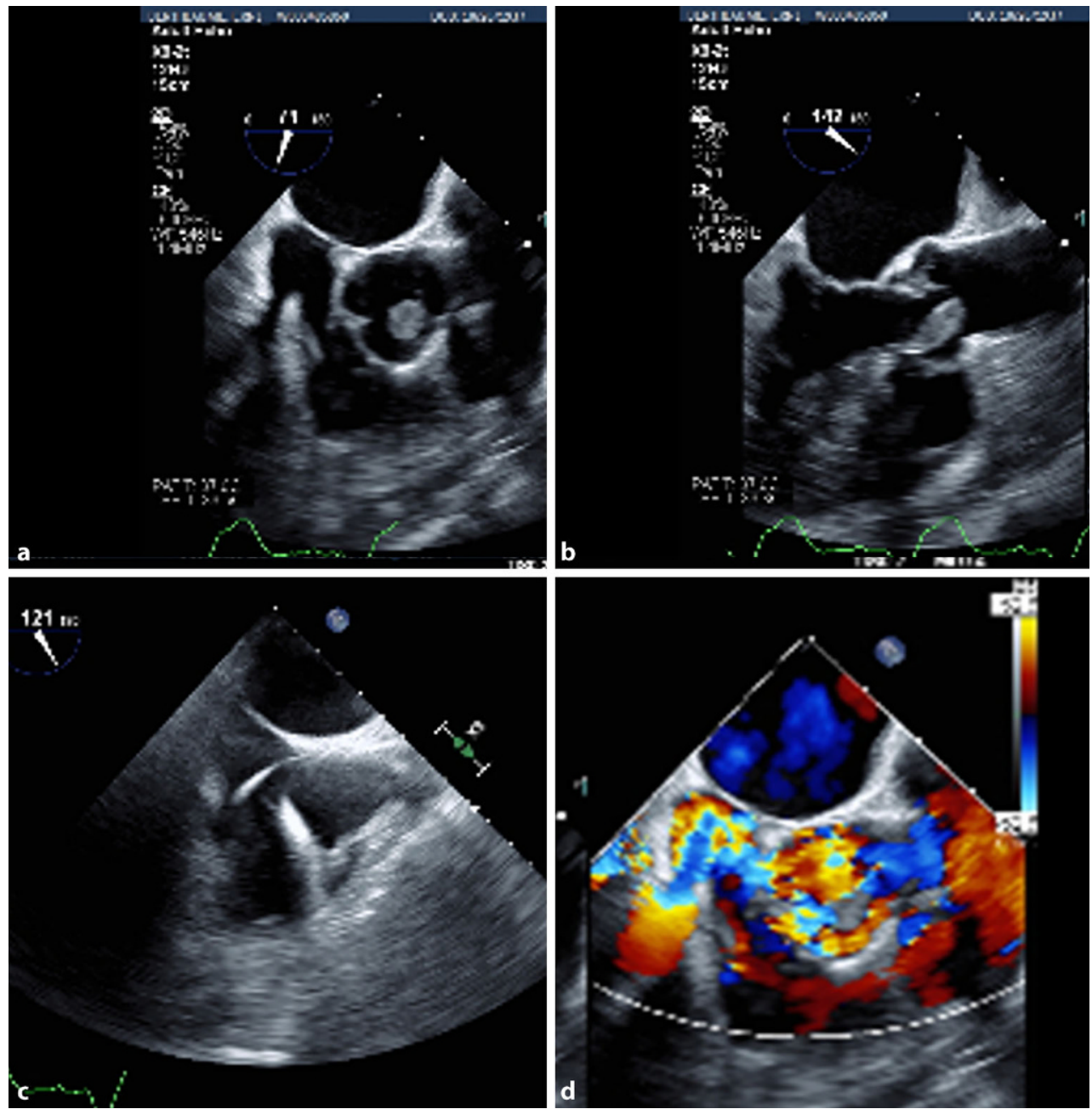

Conflict of interest K.K. Sahu, A.K. Mishra, A.A. Sherif, A. Doshi and B. Koirala declare that they have no competing interests.

Open Access This article is distributed under the terms of the Creative Commons Attribution 4.0 International License (http://creativecommons.org/licenses/by/4.0/), which permits unrestricted use, distribution, and reproduction in any medium, provided you give appropriate credit to the original author(s) and the source, provide a link to the Creative Commons license, and indicate if changes were made.

\section{References}

1. Yabes JM, Perdikis S, Graham DB, Markelz A. A rare case of Aerococcus urinae infective endocarditis in an atypically young male: case report and review of the literature. Bmc InfectDis. 2018;17(1):522.

2. Christensen JJ, Jensen IP, Faerk J, Kristensen B, Skov R, Korner B. Bacteremia/septicemia due to Aerococcus-like organisms: report of seventeen cases. Danish ALO Study Group. Clin Infect Dis. 1995;21(4):943-7.
3. Gautam A, Jalali GK, Sahu KK, Deo P, Ailawadhi S. Cardiac myeloid sarcoma: review of literature. J Clin Diagn Res. 2017;11(3):XE1-XE4.

4. DhibarDP, Sahu KK, VarmaSC, etal. Intra-cardiacthrombus in antiphospholipid antibody syndrome: an unusual cause of fever of unknown origin with review of literature. JCardiol Cases. 2016;14(5):153-6.

5. Mishra AK, Sahu KK, Lal A, Menon V. Aortic Valve Abscess: StaphylococcusEpidermidis\&InfectiveEndocarditis. QJM. 2019;pii:hcz151. https://doi.org/10.1093/qjmed/hcz151

6. Mishra AK, Nadadur S, Sahu KK, Lal A. Penetrating Aortic Ulcer Masquerading as Acute Coronary Syndrome. Am J Med Sci. 2019;pii:S0002-9629(19)30186-7.https://doi.org/ 10.1016/j.amjms.2019.04.027

7. Sahu KK, Mishra AK, Lal A, Kranis M. An interesting case of expressive aphasia: enterococcus faecalis related infective endocarditis complicating as septic emboli. QJM. 2019;pii:hcz169. https://doi.org/10.1093/qjmed/hcz169.

8. Senneby E, Göransson L, Weiber S, Rasmussen M. A population-based study of aerococcal bacteraemia in the MALDI-TOF MS-era. Eur J Clin Microbiol Infect Dis. 2016;35(5):755-62. 